\title{
ГУМАНИЗАЦИОННЫЙ КОНЦЕПТ ГОСУДАРСТВЕННОГО УПРАВЛЕНИЯ В УСЛОВИЯХ СТАНОВЛЕНИЯ СОЦИАЛЬНОГО, ПРАВОВОГО ГОСУДАРСТВА
}

\begin{abstract}
В статье исследованы основные составляющие современного процесса обеспечения прав и свобод человека и гражданина со стороны государства. Рассмотрены базовые составляющие гуманизации управления как принципа и основы государственной политики. Определены особенности европейской модели социального государства и предложены направления внедрения такой модели в Украине. Предложена авторская трактовка современных процессов трансформации государственного управления в контексте принципа гуманизма.
\end{abstract}

Ключевые слова: государственное управление, гуманизация, гуманизационный концепт, европейский контекст, европейские принципы публичного управления.

В нынешних условиях эффективная деятельность государства по обеспечению прав и свобод человека базируется на ряде концептуально новых подходов, обусловливающих коренные изменения организационно-правовых основ функционирования органов власти, в частности, гуманизации государственного управления и повышение ее авторитета, построение отношений между государством и гражданином на принципах партнерства, совершенствования организационных форм, методов и средств обеспечения прав и свобод человека и т.д.. Гуманизационный концепт государственного управления определяет в современных условиях сущность реформирования украинского общества, что приобретает особое значение в контексте европейской интеграции Украины.

Человек, его права и свободы провозглашены Конституцией Украины высшей ценностью. Их признание, соблюдение и защита - основная обязанность государства, и выполнение этой обязанности обусловило необходимость проведения глубоких преобразований в организации государственной власти в 1991-2012 гг., последовательная реализация проблемы взаимосвязи прав человека и принципа разделения государственной власти. Актуальность указанных проблем заключается как в теоретическом обосновании самих категорий «права человека» и «принцип разделения властей», так и в выявлении закономерной взаимозависимости процессов их формирования, развития и трансформационного перехода в государственно-управленческой действительности. Именно указанные

1 Olga Puszkar, Dnipropetrowski Regionalny Instytut Zarządzania Państwowego Narodowej Akademii Zarządzania Państwowego przy Prezydencie Ukrainy. 
положения является не только политико-правовой идеологии украинского общества, но и практикой совершенствования системы правового регулирования прав человека и организации государственной власти. Доминирующие стереотипы при научном анализе через исследования прав человека из социальнопсихологических, философских позиций, а принципа разделения государственной власти - с чисто государственных позиций существенно ограничивает реализацию государственно-управленческого потенциала современного правового, социального государства.

Цель статьи состоит в определении направлений организационного и институционального обеспечения формирования гуманизационного концепта государственного управления в условиях становления социального, правового государства в Украине. Достижение указанной цели видится нами через решение следующих основных исследовательских задач:

определить историко-теоретические основы становления и развития гуманизационного концепта государственного управления через категории «права и свободы человека», «социальное государство» и «правовое государство»;

раскрыть сущность современных европейских тенденций формирования гуманизационного концепта государственного управления;

- $\quad$ установить направления совершенствования организационных основ государственного управления в системе гуманизационных факторов в Украине.

Важными задачами также выступают детерминация основных принципов и структурных составляющих института прав человека в теории и практике современной науки государственного управления, применение методологии компаративно-исторического анализа при формализации гуманизационного концепта управления и на этой основе разработка основ политики обеспечения прав и свобод человека; определение способов и методов ее реализации в деятельности субъектов государственной власти, местного самоуправления, структур негосударственного управления. На основе решения таких заданий в последующем целесообразно предложить концепцию гуманизации государственного управления в контексте европейских стандартов публичного управления с целью обеспечения реализации современной парадигмы общественного управления в Украине «Государство для людей» как парадигмы построения европейского государства.

Обеспечение прав и свобод человека определяет развитие систем государственного (публичного) управления в большинстве современных стран на пути политической демократии, демократизации общественных отношений, экономического прогресса и сотрудничества, выступает одним из главных задач процесса реформирования украинского общества, что приобретает особое значение в контексте европейской интеграции Украины. Стремление украинского государства стать полноправным членом европейского сообщества направляет усилия органов публичной власти на смещение векторов деятельности с целью первоочередного обеспечения гармонизации мировых стандартов соблюдения прав и свобод человека и национальных конституционных норм.

Вхождение Украины в мировое сообщество и демократические преобразования внутри страны требуют принципиально нового отношения к институту прав и свобод человека и новых подходов к решению такой проблемы в системе публичного управления. При этом должно измениться и отношение государства к общепризнанным положениям международного права в сфере прав человека. В 
частности, после получения членства Украины в Совете Европы в 1995 году нормы европейского права активно влияют на национальную правовую систему, и она приобретает качественно новый уровень, в украинском обществе формируются, хотя и медленно, демократическая правосознание и система правоотношений, основанных на идеях обеспечения человеческого достоинства, признания и защиты основных прав и свобод личности, приоритета общечеловеческих ценностей.

Общепризнано, что права и свободы человека - это такой правовой институт общечеловеческих ценностей, для которого характерно установление единых международно-правовых стандартов. В настоящее время в мире существует значительное число институтов и механизмов, направленных на защиту прав и свобод человека и гражданина, но права личности часто нарушаются, а способы их защиты не всегда достаточно эффективны. Именно поэтому актуализируется задача как совершенствования уже имеющихся методов и средств, так и создание новых институтов, гарантирующих и обеспечивающих соблюдение прав человека на уровне государства, которые базируются на императиве гуманизационного фактора. Проблема сущности и реализации понятия «права и свободы человека и гражданина» является ключевой в жизнедеятельности общества, которое претендует на статус демократического, гуманного. Именно поэтому в мире не существует более значимой и вместе с тем сложной с точки зрения воплощения в практику существования человечества идеи, чем права и свободы человека, что обусловлено недостаточным уровнем развития нравственно-мировоззренческих критериев, правовой культуры и образования, экономических систем и отношений.

Современное понимание соотношения интересов личности и общества, соотношения интересов государства и личности не может быть соответствующим образом реализовано через противопоставление одних интересов другим, объявления государственных или личных интересов приоритетными. Такая цель может быть достигнута путем установления реального соотношения интересов в системе «гражданин - общество - государство», характеризующееся взаимодействием и взаимозависимостью интересов: в определенном смысле существует отдельно приоритет общественных интересов, приоритет личных интересов, а также сочетание личных и общественных интересов. В тоже время, следует отметить, что универсальный характер прав человека выражается в том, что они принадлежат всем людям. Как сказано в преамбуле Всеобщей декларации прав человека, «признание достоинства, присущего всем членам человеческой семьи и равных, неотъемлемых прав их является основой свободы, справедливости и всеобщего мира» ${ }^{2}$. В универсальной концепции прав человека XX века имеющиеся религиозные учения, политические доктрины, экономические, этические и правовые концепции. В основе такого подхода представления о человеческом достоинстве, как высшей ценности личности. Все мировые религии исходят из представления о духовности личности и равенства всех людей перед Богом. Вместе с тем, концепт прав человека содержит глубокий философский смысл, ведь научный

\footnotetext{
${ }^{2}$ Загальна декларація прав людини: Прийнято резолюцією 217 А (III) Генеральної Асамблеї ООН від 10 грудня 1948 р. // Права людини. Міжнародні договори України, декларації, документи / Упоряд. Ю.К. Качуренко. - 2-е вид. - К.: Юрінформ, 1992. - С. 18-24.
} 
анализ институционализации прав человека с этой точки зрения - существенная проблема, связанная с теоретическим осмыслением их практической реализации.

В современной Европе социальное, правовое государство на национальном уровне формализовано через такие институты как социальное страхование, социальная помощь, защита труда, трудовые отношения (между работниками и работодателями, профсоюзами и союзами работодателей) и обеспечение свободного доступа к рынку труда ${ }^{3}$. Некоторые из них нашли применение в Европейском Союзе, некоторые остались на национальном уровне. Стоит отметить, что с позиций демократического управления, социальное государство - это государство, которое обеспечивает каждому гражданину достаточные условия существования, социальной защищенности, соучастия в управлении производством. То есть, в широком смысле базовой функцией демократического управления должен выступать императив создания почти одинаковых жизненных возможностей, прежде всего, для самореализации личности в социуме. Именно поэтому деятельность публичной администрации в таком государстве направлена на общее благосостояние, утверждение в обществе социальной справедливости. При этом именно государство минимизирует имущественное отличие, обеспечивает трудоустройство, политический плюрализм и одновременно - политическую стабильность, то есть то, что получило в современной науке название стабильного жизненного пространства.

В контексте Европейской социальной модели довольно часто речь идет о социальной политике, реализация которой оказалась возможной за счет демократических принципов управления, через применение принципов европейского публичного управления. В тоже время, следует обратить внимание на некоторые проблемные стороны публичного управления в контексте формирования европейской социальной модели. Ведь обеспечение мобильности рабочей силы и реализация свободы услуг по всему Европейскому Союзу поставили под сомнение отдельные положения социального государства. Это, прежде всего, существенные диспропорции в социальном развитии отдельных территорий, проблематика прав человека в миграционной среде, диспропорции экономического развития. Соответственно, Европейской Комиссией были предприняты жесткие санкции по внедрению стандартов социальной политики. Кроме того, существенный вклад в формирование стандартов демократического управления внесла Хартия об основных правах и свободах $2000 \Gamma^{4}$. И хотя эти меры не всегда соответствуют потребностям государств - членов ЕС в области социального государства, они необходимы для интеграции Европейского Союза и развития внутреннего рынка, нацелены именно на достижение этих результатов. Здесь, с точки зрения неофункционального подхода к евроинтеграционному процессу мы можем говорить о том, что эти процессы, функциональные для ЕС, оказались дисфункциональными для отдельных социальных государств-членов Европейского Союза.

\footnotetext{
${ }^{3}$ М.М. Гуренко, Зародження та становлення ідеї гарантій прав $і$ свобод людини $і$ громадянина у ліберальній теоретико-правовій думиі: Монограф. - К.: Логос, 2000. - 167 с.

${ }^{4}$ С.П. Добрянський, Хартія Свропейського Союзу про основні права як втілення здобутків загальноі теорії прав людини // Бюл. Мін-ва юстиції України. - 2003. - № 5. - С. 42-48.
} 
Утверждение Европейской социальной модели в целом соответствует общему научному подходу к концепции «режимов благосостояния» (welfare regimes). Сочетание в таком формате либеральных, корпоративных и универсальных подходов позволило наработать единую методологию развития европейских государств - понимание эффективности и рациональности феномена социальной справедливости и социального выравнивания для экономического развития (при этом социальный сегмент не является затратным фактором). Важно, что такая модель предполагает, что экономическое развитие должно способствовать социальному благосостоянию. А основой такого положения вещей выступает унификация. «Европейская социальная модель опирается на значительные экономические достижения, высокий уровень социальной защищенности, высокий уровень образования и социальный диалог» ${ }^{5}$.

Ранее политика как важная составляющая конституирования социального, правового государства фактически решала две задачи: с одной стороны, определяла темпы и пропорции экономического развития, с другой - обеспечивала формирование фондов общественного потребления. Фактически государство способствовало утверждению патерналистских ожиданий у населения, к минимуму сведя личную ответственность человека за самообеспечение и экономический самозащиту. Становление социального рыночного хозяйства требует приоритетного развития системы социального обеспечения путем реализации адекватной социальной политики. Приоритетность в данном случае обусловлена уникальной ролью государства как института, гарантирует обеспечение населения определенным набором социальных благ и гарантий.

Итак, задачи, поставленные перед институтами публичной власти социального, правового государства, во-первых, должны быть детерминированы законодательно закрепленными обязательствами государства по социальной защите населения в случае непредвиденных обстоятельств. А во-вторых, они должны быть связаны с необходимостью обеспечения приемлемого стандарта жизни для групп населения с низким доходом. То есть, социальная политика, имея четкие цели, функции, принципы и структуру, по содержанию должна содержать конкретные механизмы решения общественных проблем и инструменты собственного совершенствования.

Исходя из опыта становления социальной политики ЕС, отметим, что именно надлежащий экономический базис позволил сформировать устойчивую модель социальных отношений в европейском демократическом обществе. Характерно, что все современные развитые общества опираются на универсальную модель институциональных взаимоотношений, определенных форматом социальноэкономической системы. Конструкция этой модели, скрепленная идеей социальной солидарности, непосредственно связана с понятием социального партнерства как формы многостороннего общественного взаимодействия. Именно поэтому формирование социальной политики в Украине в контексте европейского опыта нуждается в собственной концептуальной основе, разработке отечественной социальной модели, которая интегрирует проблемный анализ социальной стабильности на центральном и региональном уровнях. При этом актуализируется

\footnotetext{
5 М.М. Гуренко, Розвиток політико-правової думки про гарантї прав та свобод людини та громадянина: Монографія.-Київ: Логос,2002.-252 с.
} 
наработка действенных механизмов социального регулирования общественных отношений. Опыт социально-экономического развития постиндустриальных обществ конца XX - начала XXI века доказывает, что социальный корпоративизм можно назвать стратегическим принципом построения и функционирования современного государства благосостояния. Таким образом, формирование системы социального партнерства на новом реализационном уровне становится первостепенным фактором для определения современной архитектуры гражданского общества, обеспечивает реализацию стандартов демократического управления в Украине.

Современное восприятие концепции социального, правового государства базируется на многообразии сущности института государства. Изначально выполнения государством функции реализации общественно важных дел дает основание для признания социальной деятельности одним из непременных аспектов сущности института государства. При этом социальная направленность государственного управления в условиях глобализационных процессов сейчас сохраняет приоритетность среди других видов, поскольку гуманизационные основы государственно-управленческой деятельности предусматривают осуществление со стороны органов власти такого воздействия на общественные отношения, основанные на учете потребностей всех групп. Естественно, средством оптимизации социального развития в Украине является внедрение зарубежного опыта социального партнерства, социальной направленности механизмов государственного управления в странах Европы.

Утверждение механизмов, способных гарантировать неукоснительное соблюдение определенных Конституцией и законами Украины прав и свобод граждан, существенное усиление контроля институтами гражданского общества за деятельностью правительства, министерств и других органов исполнительной власти является одним из ключевых задач административной реформы в Украинском государстве. Права каждого должны стать не чем-то производным или второстепенным среди задач органов государственной власти, а их главной целью и принципиально изменить историческую парадигму отношений между государством и человеком. На смену идеологии господства государства над личностью должна прийти идеология служения государства интересам человека. Такой переход возможен только при условии реального воплощения в жизнь предусмотренного Конституцией Украины принципа верховенства права (ст. 8), который требует подчинения деятельности государственных институтов потребностям реализации и защиты прав человека, обеспечения их приоритета среди всех других ценностей демократического общества ${ }^{6}$.

В современных условиях значительную актуальность приобретает исследование условий и тенденций развития государственности в Украине как составной части европейского демократического сообщества, и особенно развития теоретической концепции демократического, социального правового государства. Сейчас, в процессе реформирования направлений государства и проведения системных реформ игнорирование гуманизационного фактора государственно-управленческих отношений вызвало значительные деформации государственной политики,

\footnotetext{
${ }^{6}$ Конституція України // Відомості Верховної Ради України. - 1996. - № 30. - Ст.141.
} 
спровоцировало разрыв в возможностях проведения эффективной социальной политики и реальной способности удовлетворить интересы социальных групп.

В частности, в теоретическом аспекте - это проблемная сфера современного государства через либерализм и парадигму «государство для людей»; государственные гарантии развития личности; реализация программы государственной защиты или только государственная поддержка отдельных социальных слоев формирование государственного патернализма или суверенитет семьи. Такие альтернативные подходы к осуществлению со стороны государства базовой функции - социальной - обусловленные одновременную реализацию как рыночного либерального подхода в экономике, так и сохранении в украинской ментальности элементов советского принципа равенства всех граждан. Время, в практическом аспекте стоит задача преодоления вышеупомянутых дихотомий через выработки новых моделей общественного партнерства, минимизирующих кризисные явления, и одновременно - обеспечивают поступательное развитие государства даже в условиях мирового экономического кризиса.

Исследование теоретико-методологических основ становления системы государственного управления в Украине, тенденций и особенностей влияния современных европейских интеграционных процессов на национальные системы государственного управления доказывают, что в Украине за основу построения отечественной правовой системы взята европейская гуманистическая концепция, а человек (конкретное физическое лицо) признается наибольшей социальной ценностью. Вместе с тем историко-теоретический анализ позволяет актуализировать современный формат методологического обеспечения государственного управления, который заключается в системном исследовании реформирования государственного управления в Украине в контексте развития европейских интеграционных процессов в соответствии с принципиально новым условиям государства - гуманизации государственного управления в формате идеологемы «государство для людей »и формирования национального идеологического концепта« Украина - европейское государство».

Сущность гуманизацийного концепта государственного управления, соответственно, предлагается рассматривать через систему принципов гуманизации государственного управления: принцип равных возможностей, принцип человеческого достоинства, принцип социальной справедливости, принцип солидаризма, принцип социальных обязательств, принцип субсидиарности, принцип относительной независимости общественных отношений. На этом основании считаем, что с позиций современных научных подходов к социализации управления, субъект социальной политики (социальные группы, имеющие в своих руках властные механизмы в социальной сфере), обеспечивая достижение благосостояния в обществе (общество в данном случае выступает как совокупность исторически сложившихся форм совместной деятельности людей), реализует принцип социальной справедливости, при определенных ограничениях выступает как общая цель деятельности социальной сферы общественных отношений.

Важность и актуальность формирования гуманизационного концепта государственного управления определена тем, что является органическим компонентом демократического политического пространства, инструментом общественных отношений. Гуманизационный концепт не всегда был адекватен своему значению в обществе, однако эволюционировал, модифицировались его 
основы, утверждались базовые ценности. Именно в процессе конституирования гуманизационного концепта состоялось утверждение европейских социальных, правовых государств. При этом достигнутые на современном этапе развития европейские ценности позволяют формировать и разрабатывать новые подходы в определении собственно гуманизационного концепта государственного управления как системы понятий и представлений о сущностных характеристиках содержания государственного управления, направленного на реализацию прав и свобод граждан, формирование средств и способов обеспечения реализации прав и свобод со стороны органов власти, при наличии внешних стандартов, которые должны быть соблюдены в процессе реализации прав и свобод. Гуманизационный концепт государственного управления в организационно-правовом и административнополитическом смысле выступает как система общеобязательных правил, процедур и принципов правообеспечения в сфере государственного управления, актов правотворчества государственных органов и органов местного самоуправления. В социо-гуманитарном смысле - как совокупность объективно существующих экономических, политических, культурных, духовных и других обстоятельств общественного развития, которые предопределяют содержание нормотворческой деятельности в административно-правовой сфере, регулируют процесс формирования рациональной политики государства.

В своем истинном значении гуманизационный концепт предопределяет направления развития систем государственного (публичного) управления. Одновременно происходит качественная трансформация государственноуправленческих отношений, существенно усиливается личностная компонента публичного управления, конкретизируются субъектно-объектные отношения управления.

\section{ЛИТЕРАТУРА}

[1] Загальна декларація прав людини: Прийнято резолюцією 217 А (III) Генеральної Асамблеї ООН від 10 грудня 1948 р. // Права людини. Міжнародні договори України, декларації, документи / Упоряд. Ю.К. Качуренко. - 2-е вид. - К.: Юрінформ, 1992. - С. 18-24.

[2] Гуренко М.М., Зародження та становлення ідеї гарантій прав і свобод людини $і$ громадянина у ліберальній теоретико-правовій думиі: Монограф. - К.: Логос, 2000. $-167 \mathrm{c}$.

[3] Гуренко М.М., Розвиток політико-правової думки про гарантії прав та свобод людини та громадянина: Монографія.-Київ: Логос,2002.-252 с.

[4] Добрянський С.П., Хартія Свропейського Союзу про основні права як втілення здобутків загальної теорії прав людини // Бюл. Мін-ва юстиції України. - 2003. - № 5. - C. 42-48.

[5] Конституція України // Відомості Верховної Ради України. - 1996. - № 30. Ст.141. 


\section{HUMANISTYCZNA KONCEPCJA ADMINISTRACJI PUBLICZNEJ W WARUNKACH KSZTALTOWANIA SOCJALNEGO, PRAWNEGO PAŃSTWA}

W artykule zbadano podstawowe elementy współczesnego procesu gwarantowania przez państwo praw i wolności człowieka i obywatela. Rozpatruje się bazowe składniki humanizacji zarządzania jako zasady i podstawy polityki państwa. Określono osobliwości europejskiego modelu państwa opiekuńczego oraz zaproponowano kierunki realizacji tego modelu w Ukrainie. Zaproponowano autorską interpretację współczesnych procesów transformacji administracji publicznej w kontekście zasady humanizmu.

Słowa kluczowe: zarządzanie państwem, humanizacja, koncept humanizacyjny, kontekst europejski, europejskie zasady administracji publicznej.

\section{HUMAN CONCEPT OF PUBLIC ADMINISTRATION UNDER FORMATION OF SOCIAL AND CONSTITUTIONAL STATE}

In the paper the basic components of the modern process of securing the rights and freedoms of the citizens of the state are researched. The basic components of human governance as the principle and basis of public policy are described. The features of the European model of the welfare state and directions of the implementation of this model in Ukraine are determined. The author 's interpretation of the contemporary processes of transformation of public administration in the context of the principle of humanity is discussed.

Keywords: public administration, humanization, humanization concept, a European context, the European principles of public administration.

DOI:10.7862/rz.2012.einh.28 